\title{
Trunk rotation due to persistence of primitive reflexes in early school-age children
}

\author{
Ewa Z. Gieysztor ${ }^{\mathrm{A}-\mathrm{D}, \mathrm{F}}$, Ludwika Sadowska ${ }^{\mathrm{A}, \mathrm{E}, \mathrm{F}}$, Anna M. Choińska ${ }^{\mathrm{A}, \mathrm{E}, \mathrm{F}}$, Małgorzata Paprocka-Borowicz ${ }^{\mathrm{E}, \mathrm{F}}$ \\ Department of Physiotherapy, Faculty of Health Sciences, Wroclaw Medical University, Poland \\ A - research concept and design; $B$ - collection and/or assembly of data; $C$ - data analysis and interpretation; \\ $\mathrm{D}$ - writing the article; $\mathrm{E}$ - critical revision of the article; $\mathrm{F}$ - final approval of the article
}

Address for correspondence

Ewa Gieysztor

E-mail: gieysztor.ewa@gmail.com

Funding sources

None declared

Conflict of interest

None declared

Received on August 24, 2016

Reviewed on October 27, 2016

Accepted on December 1, 2016

\section{Abstract}

Background. The angle of trunk rotation (ATR) is a measurement that allows an objective assessment of a growing child's spine. Early detection of trunk rotation prevents the progression of scoliosis. One of the factors that predispose children to the formation of faulty posture may be primitive reflexes, which should be integrated in the central nervous system (CNS) by the age of one year. If retained, primitive reflexes affect children's physical development as well as their development at school.

Objectives. The aim of the study was to determine the prevalence of trunk asymmetry and the persistence of primitive reflexes and their inter-relationships in early school-age children.

Material and methods. In this population-based survey, 61 children, average age 6.3 years (SD \pm 1.43 ), were examined. The ATR was examined using a scoliometer. The degree of integration of reflexes was assessed using tests developed by S. Goddard to assess the asymmetrical tonic neck reflex (ATNR), symmetrical tonic neck reflex (STNR), and spinal Galant reflex (SGR) on a 0-4 scale. Spearman's rank correlation coefficient and the $x^{2}$ test were used in the statistical analysis.

Results. In almost half of the children body rotation was observed, in most cases toward the right $(p=0.012)$. This asymmetry was positively correlated with non-integrated Galant reflex on the same side $(r=0.335$, $p=0.050$ ). The presence of trunk rotation is associated with sex: There was higher frequency of asymmetry among the girls than among the boys.

Conclusions. In the evaluation of scoliosis, it could be useful to examine primitive reflexes as a possible reason for trunk rotation. In the treatment of scoliosis, primitive reflex integration methods should be used in some cases.

Key words: children, the angle of trunk rotation, primitive reflex integration, scoliosis

DOI

$10.17219 /$ acem $/ 67458$

\section{Copyright}

Copyright by Author(s)

This is an article distributed under the terms of the

Creative Commons Attribution Non-Commercial License

(http://creativecommons.org/licenses/by-nc-nd/4.0/) 
Axial rotation of the vertebrae is a feature of spinal deformity in idiopathic scoliosis (IS). Rotation pivots around the long axis of the spine and results in rib humps in the thoracic region and muscle shafts in the lumbar region. Their size depends on the scoliosis angle measured using the Cobb method. ${ }^{1}$

There are several hypotheses regarding the underlying cause of trunk rotation in scoliosis. Among them, asymmetrical hip joint rotation range has been considered. ${ }^{2}$ Many of them define scoliosis as idiopathic. On the other hand, in pediatric neurology it has been observed that bad posture and repeated movements are caused by primitive reflexes which, if not integrated, could lead to asymmetry in various body parts and could also have an impact on spine rotation. ${ }^{3}$

Primitive reflexes are a natural part of prenatal and neonatal neurological development, but if they persist after 6-8 months of a child's life, they have an impact on the child's neurological, emotional and physical development. ${ }^{4-6}$ In the present study we focused on 3 primitive reflexes that we have found to have the greatest impact on posture: the asymmetric tonic neck reflex (ATNR), the symmetric tonic neck reflex (STNR), and the spinal galant reflex (SGR).

The angle of trunk rotation is the parameter measured by the Bunnell scoliometer. It is an objective assessment technique consisting of an easy and economical examination, and it can be used widely to monitor or prevent scoliosis. ${ }^{7}$ There is a precise formula for converting scoliometer angles to Cobb angles. For example, $5^{\circ}$ on the scoliometer is an $11^{\circ} \mathrm{Cobb}$ angle, and $7^{\circ}$ on the scoliometer corresponds to a $20^{\circ} \mathrm{Cobb}$ angle. ${ }^{8,9}$

In this paper we investigated whether persistent primitive reflexes co-exist with trunk rotation. The hypothesis is that persistent asymmetric primitive reflexes have an impact on trunk rotation.

\section{Material and methods}

\section{Participants}

The study was approved by the Wroclaw Medical University Ethics Committee (Wrocław, Poland). All the parents of the patients were informed of the purpose and process of the examinations and gave their written consent prior to the study.

The data was collected from 61 healthy children from schools in Lower Silesia (Poland). The participants' age range was 5-9 years old; the average age was 6.3 years ( $\mathrm{SD} \pm 1.43$ ). The group included 36 girls and 25 boys. Conditions for exclusion were special educational and rehabilitation needs. Each child was assessed individually using primitive reflex tests (ATNR, STNR and SGR), and a trunk rotation test with Bunnell's scoliometer.

\section{Measurement of primitive reflexes}

The tests were carried out with the child in a quadruped position with hips flexed to $90^{\circ}$, elbows extended, hands flat, fingers extended, and head in a neutral position. ${ }^{5,10}$

In the asymmetrical tonic neck reflex test, the examiner gently and slowly rotated the child's head to both sides. The procedure was carried out passively with a stop point at the midline. This sequence was repeated 4 times. The ATNR was measured on both the left side (ATNR L) and the right side (ATNR R).

The symmetrical tonic neck reflex was tested by the examiner with the child's head passively bent and extended. The STNR was measured for flexion (STNR FLX) and extension (STNR EXT).

The spinal Galant reflex was tested by stimulating the side of the back, laterally from the spine. The test was carried out on both the left side (SGR L) and right side (SGR R).

The classification of the reflexes was done using Goddard's 5-point rating scale (0-4). ${ }^{11}$ The higher the children scored on the primitive reflex test, the lower the degree of primitive reflex integration they presented.

\section{Measurement of trunk rotation}

The children were also given trunk rotation tests using Bunnell's scoliometer. ${ }^{7,8}$ The measurements were conducted in the Adams forward bend test position. The results were classified in 4 levels: $0,1-3,4-6,>7$. Level 0 means no abnormality, and the other levels indicate the degree of deformity in the trunk. The higher the scoliometer measurement, the greater the trunk rotation.

\section{Statistical analysis}

The statistical analysis was carried out using STATISTICA v. 12 software (StatSoft Inc., Tulsa, USA). Descriptive statistics were computed for all the variables. The results are presented as mean and standard deviation (SD \pm ) or percentages. The normality of distribution was assessed using the Shapiro-Wilk test. The occurrence of right and left rib humps and the occurrence of primitive reflexes in relation to sex were calculated using the $\chi^{2}$ test with the Yates correction. Spearman's rank correlation was applied for dependency between variables. Differences were considered statistically significant when $\mathrm{p}<0.05$.

\section{Results}

Based on the tests, most of the children had non-persistent STNR FLX, which is the most integrated reflex among those studied. Nearly half of the group had retained SGR on both sides. ATNR P and STNR EXT occurred in over half of the children examined. The most frequently occurring persistent reflex was ATNR L, and the least frequently 
Table 1. Occurrence of primitive reflexes on a 5-point scale (0-4) in relation to sex

\begin{tabular}{|c|c|c|c|c|c|c|c|c|c|c|c|c|c|c|c|c|c|c|c|c|c|c|c|c|}
\hline \multirow{4}{*}{ Scale } & \multicolumn{24}{|c|}{ Reflex } \\
\hline & \multicolumn{4}{|c|}{ SGR L } & \multicolumn{4}{|c|}{ SGR R } & \multicolumn{4}{|c|}{ ATNR L } & \multicolumn{4}{|c|}{ ATNR R } & \multicolumn{4}{|c|}{ STNR FLX } & \multicolumn{4}{|c|}{ STNR EXT } \\
\hline & \multicolumn{2}{|c|}{$0^{x}$} & \multicolumn{2}{|c|}{ q } & \multicolumn{2}{|c|}{$0^{*}$} & \multicolumn{2}{|c|}{ q } & \multicolumn{2}{|c|}{$0^{x}$} & \multicolumn{2}{|c|}{ q } & \multicolumn{2}{|c|}{$0^{x}$} & \multicolumn{2}{|c|}{ १ } & \multicolumn{2}{|c|}{$0^{x}$} & \multicolumn{2}{|c|}{ q } & \multicolumn{2}{|c|}{$0^{x}$} & \multicolumn{2}{|c|}{ q } \\
\hline & $\%$ & $n$ & $\%$ & $n$ & $\%$ & $\mathrm{n}$ & $\%$ & $\mathrm{n}$ & $\%$ & $n$ & $\%$ & $n$ & $\%$ & $\mathrm{n}$ & $\%$ & $n$ & $\%$ & $\mathrm{n}$ & $\%$ & $\mathrm{n}$ & $\%$ & $n$ & $\%$ & $\mathrm{n}$ \\
\hline 0 & 42 & 10 & 38 & 14 & 42 & 10 & 54 & 20 & 17 & 4 & 19 & 7 & 29 & 7 & 32 & 12 & 79 & 19 & 81 & 30 & 29 & 7 & 32 & 12 \\
\hline 1 & 21 & 5 & 16 & 6 & 29 & 7 & 8 & 3 & 33 & 8 & 51 & 19 & 33 & 8 & 49 & 18 & 13 & 3 & 11 & 4 & 42 & 10 & 38 & 14 \\
\hline 2 & 17 & 4 & 24 & 9 & 17 & 4 & 22 & 8 & 25 & 6 & 19 & 7 & 13 & 3 & 11 & 4 & 4 & 1 & 3 & 1 & 17 & 4 & 19 & 7 \\
\hline 3 & 17 & 4 & 14 & 5 & 8 & 2 & 8 & 3 & 17 & 4 & 8 & 3 & 25 & 6 & 5 & 2 & 4 & 1 & 3 & 1 & 13 & 3 & 3 & 1 \\
\hline 4 & 4 & 1 & 5 & 2 & 4 & 1 & 2 & 2 & 8 & 2 & 0 & 0 & 0 & 0 & 0 & 0 & 0 & 0 & 0 & 0 & 0 & 0 & 3 & 1 \\
\hline$p$-value & \multicolumn{4}{|c|}{$0.949^{*}$} & \multicolumn{4}{|c|}{$0.311^{*}$} & \multicolumn{4}{|c|}{$0.238^{*}$} & \multicolumn{4}{|c|}{$0.154^{*}$} & \multicolumn{4}{|c|}{$0.217^{*}$} & \multicolumn{4}{|c|}{$0.649^{*}$} \\
\hline
\end{tabular}

${ }^{*} x^{2}$ test.

occurring persistent reflex was STNR FLX. Neither STNR, FLX nor ATNR R were found at the maximum intensity in any of the children.

A comparison of the data from the boys and girls is shown in Table 1. The persistence of primitive reflexes differed between the sexes, especially in ATNR L and R. The girls' results were better in the integration of the reflexes, but the difference wasn't statistically significant ( $\mathrm{p}>0.050$ ).

The participants' scoliometer rates in the trunk rotation tests are shown in Table 2. Right rotation is more frequent than left rotation, and the difference in the frequency of right and left rotation is statistically significant at $\mathrm{p}=0.012$.

Table 2. Occurrence of right and left rib humps. The difference between right- and left-sided rib hump occurrence is statistically significant at $p=0.012\left(X^{2}\right.$ test $)$

\begin{tabular}{|c|c|c|c|c|}
\hline \multirow{2}{*}{$\begin{array}{c}\text { Scoliometer } \\
\text { rate }\end{array}$} & \multicolumn{2}{|c|}{ Right-sided rib hump } & \multicolumn{2}{|c|}{ Left-sided rib hump } \\
\cline { 2 - 5 } & $\%$ & $n$ & $\%$ & $n$ \\
\hline 0 & 54 & 33 & 75 & 46 \\
\hline $1-3$ & 20 & 12 & 10 & 6 \\
\hline $4-6$ & 24 & 15 & 12 & 7 \\
\hline 7 & 2 & 1 & 3 & 2 \\
\hline
\end{tabular}

When the scoliometer results were considered in relation to the children's sex, we found that trunk rotation occurred moderately more frequently in girls $(\mathrm{p}=0.296)$. In the group of boys, trunk rotation was observed in 54\%, while in the group of girls it was seen in $57 \%$. The difference in the frequency of right or left rotation was also compared between boys and girls; $38 \%$ of the boys had right trunk rotation, while among the girls it was $49 \%$. The results were not statistically significant ( $\mathrm{p}=0.181$ ).

The statistical analysis showed a correlation between the persistence of primitive reflexes and trunk rotation. A significant correlation was found between the spinal Galant reflex and right trunk rotation $(\mathrm{p}<0.050)$. There was no statistically significant correlation between other primitive reflexes and trunk rotation $(\mathrm{p}>0.050$; Table 3).
Table 3. Correlations between reflexes and trunk rotation

\begin{tabular}{|l|c|l|}
\multicolumn{1}{c|}{ Reflex } & R rotation & L rotation \\
\hline ATNR L & $r=0.151$ & $r=-0.100$ \\
\hline ATNR R & $r=0.079$ & $r=-0.127$ \\
\hline STNR FLX & $r=0.040$ & $r=-0.205$ \\
\hline STNR EXT & $r=0.109$ & $r=0.002$ \\
\hline SGR L & $r=0.156$ & $r=-0.134$ \\
\hline SGRR & $r=0.335^{*}$ & $r=0.044$ \\
\hline
\end{tabular}

* significant correlation (Spearman's rank correlation coefficient).

\section{Discussion}

Studies on trunk rotation have been widely conducted on children with IS. ${ }^{2,12}$ There are also many studies about the effectiveness of various kinds of scoliosis treatment. ${ }^{13-17}$ Our work contributes to the discussion of what the causes of IS may be. The present study shows that one of the causes of trunk rotation may lie in neurodevelopmental disturbances. Asymmetry in the muscle tone induced by an involuntary response caused by a reflex, which is repeated each time the child moves his or her head, causes changes in the nervous tracts, and even though the intensity of the reflex decreases with age, motor patterns are impeded. Nearly half of the children examined in this study had a low level of primitive reflex integration, and this correlated with the trunk rotation screening results. In our study $2-3 \%$ of the results were positive for trunk rotation values greater than or equal to $7^{\circ}$ on the scoliometer. These results correspond with those of other researchers: Bunnell reported 2-3\%, Yawn et al. 4.1\% and Fong et al. 0.1-7.45.9,18,19

We have also found that most of the trunk rotation was situated on the right side of the trunk. This is similar to the results reported by Grivas et al., who found that left trunk asymmetry was less common than right in a group of 2071 children $5.5-18$ years old. ${ }^{20}$ They also mentioned that girls were found to present a higher frequency of asymmetry than boys. In our study we also found a higher frequency of asymmetry in girls than in boys. 
Among the girls in our study trunk rotation of various intensities was observed in 57\%, while it was noted in 54\% of the boys.

We have found no studies dealing with the impact of persistent primitive reflexes on posture, and therefore we have started to investigate the issue. In this study we found persistent primitive reflexes at the maximum level (4 points) in $2-5 \%$ of the participants. Grzywniak, whose research was conducted in two groups of healthy children (one group with learning difficulties, and a second group of children growing up in an orphanage), indicated that none of the children had 4 points in any of the examined reflexes, but the author emphasized that if a child has one persistent primitive reflex, he or she must also have another, in a state of mutual influence. ${ }^{21}$ Neurodevelopmental problems can impact a child's progress in many areas, and this is therefore worth studying.

Scoliosis is not only a health problem, but also results in high costs to society. ${ }^{22}$ Observations published by Chowańska et al. suggest that the use of a scoliometer decreases the costs of screening for scoliosis and facilitates to initiation of proper treatment. ${ }^{23}$

Examinations in cases of trunk rotation or scoliosis should involve not only physical examinations of asymmetry, but also screening for primitive reflexes. If some of them persist, it is justified to conduct primitive reflex integration therapy to break the cycle of involuntary movements and teach children new corrective patterns used in some methods of physiotherapy treatment. If primitive reflex integration therapy is undertaken, correction at the basic neurological level could stop the progression of scoliosis.

In conclusion, there is a need for ongoing research to observe the impact of reflexive movements on body posture. However, applying reflex integration therapy in the treatment of scoliosis and posture defects may help eliminate neurological causes of rotation of the spine in selected cases.

\section{References}

1. Krawczyński A, Kotwicki T, Szulc A, Samborski W. Clinical and radiographic measurement of the rotation of the vertebrae in patients with idiopathic scoliosis. Ortop Traumatol Rehabil. 2006;6:602-607.

2. Kotwicki T, Walczak A. Szulc A. Trunk rotation and hip joint range of rotation in adolescent girls with idiopathic scoliosis: does the' dinner plate' turn asymmetrically? Scoliosis. 2008;3:1.

3. Ellis MD, Drogos J, Carmona C, Keller T, Dewald JPA. Neck rotation modulates flexion synergy torques, indicating an ipsilateral reticulospinal source for impairment in stroke. J Neurophysiol. 2012; 11:30963104.

4. Gieysztor EZ, Choińska AM, Paprocka-Borowicz M. Persistence of primitive reflexes and associated motor problems in healthy preschool children. Arch Med Sci. 2018;1:167-173.

5. Goddard-Blythe S, Hyland D. Screening for neurological dysfunction in the specific learning difficulty child. Br JOccup Ther. 1998;61:459-464.

6. Sadowska L. Vaclav Vojta's neurokinesiological concept for the diagnosis and therapy of children with disturbances of motor development. Ortop Traumatol Rehabil. 2001;3:519-526.

7. Amendt LE, Ause-Ellias KL, Eybers JL. et al. Validity and reliability testing of the Scoliometer ${ }^{\oplus}$. Phys Ther. 1990;70:108-117.

8. Bunnell WP. An objective criterion for scoliosis screening. J Bone Jt Surg Am. 1984;66:1381-1387.

9. Bunnell WP. Selective screening for scoliosis. Clin Orthop. 2005;434: 40-45.

10. Goddard-Blythe S. Attention, Balance and Coordination: The A.B.C. of Learning Success. Wiley-Blackwell; 2009.

11. Goddard-Blythe $S$. The role of primitive survival reflexes in the development of the visual system. Journ Behav Opt. 1995;6(2):31-36.

12. Samuelsson $L$, Noren $L$. Trunk rotation in scoliosis the influence of curve type and direction in 150 children. Acta Orthop Scand. 1997; 68:273-276.

13. Białek $M, M^{\prime}$ hango $A$, Kotwicki T. Monitoring of changes in trunk rotation during scoliosis physiotherapy. Scoliosis. 2007;2:1.

14. Wnuk B, Blicharska I, Błaszczak E, Durmała J. The impact of the derotational mobilization of manual therapy according to KaltenbornEvjenth on the angle of trunk rotation in patients with adolescent idiopathic scoliosis - Pilot study. Direct observation. Ortop Traumatol Rehabil. 2015;17:343-350.

15. Białek M, Kotwicki T, M'hango A, Szulc A. Angle of trunk rotation in primary and compensatory scoliotic curve in children after individual rehabilitation with FITS method. Ann Acad Med Siles. 2007;61:45-48.

16. Kim KD, Hwangbo PN. Effects of the Schroth exercise on the Cobb's angle and vital capacity of patients with idiopathic scoliosis that is an operative indication. J Phys Ther Sci. 2016;28:923-926.

17. Borysov M, Borysov A. Scoliosis short-term rehabilitation (SSTR) according to 'Best Practice' standards - are the results repeatable? Scoliosis. 2012;7:1.

18. Yawn BP, Yawn RA, Hodge D, et al. A population-based study of school scoliosis screening. JAMA. 1999;282:1427-1432.

19. Fong DY, Lee CF, Cheung KM, et al. A meta-analysis of the clinical effectiveness of school scoliosis screening. Spine. 2010;35:1061-1071.

20. Grivas TB, Vasiliadis ES, Koufopoulos G, et al. Study of trunk asymmetry in normal children and adolescents. Scoliosis. 2006;1:19.

21. Grzywniak C. The effect of the form of persistent trace reflexes to rise the difficulties of school. Szk Spec. 2010;98-112.

22. Kowalski IM, Dwornik M, Lewandowski R, et al. Early detection of idiopathic scoliosis - analysis of three screening models. Arch Med Sci. 2015;11:1058-1064.

23. Chowańska J, Kotwicki T, Rosadziński K. Sliwiński Z. School screening for scoliosis: Can surface topography replace examination with scoliometer? Scoliosis. 2012;7:9. 